\title{
Experience with cinacalcet in familial hypocalciuric hypercalcemia resulting from inactivating mutations in calcium sensing receptor (CaSR)
}

\begin{abstract}
Background: Familial hypocalciuric hypercalcemia $(\mathrm{FHH})$ is usually characterized by asymptomatic hypercalcemia, hypocalciuria and normal PTH. The diagnosis of $\mathrm{FHH}$ is often incidental and seldom require any medical intervention.

Patient description: We are reporting Case 1 an 8 years old female incidentally diagnosed with hypercalcemia at the age of 3 years. She had complaints of constipation, polyuria and nocturia. Urinary calcium excretion was extremely low. A trial of Cinacalcet was initiated at 7 years of age, which provided completes symptomatic relief, increased urinary calcium excretion and decreased serum calcium levels. Case 2 is a 7 year old male was evaluated for leg cramps and high serum calcium level (11.3 $\mathrm{mg} / \mathrm{dL}$ ). The patient complained of occasional leg pains. Case 3 is a 6 year old boy the younger brother of Case 2 was referred for high serum calcium level $(11.1 \mathrm{mg} / \mathrm{dL})$. Family history is significant for hypercalcemia in their father. After confirmation of a CaSR mutation, both were started on Cinacalcet $30 \mathrm{mg}$ twice a day. Over the course of treatment the calcium levels were normalized and leg pain resolved in case 2 .

Result: Mutation analysis of the CASR gene in case 1 revealed a missense mutation (CGA-CAA, R185Q). In case 2 and case 3 a heterozygous mutation (GCC->ACC, A194T) was found in the extracellular domain in the CaSR encoded by exon 4.

Conclusion: We are reporting a novel mutation of CaSR in a severe presentation in case 1 and lack of symptoms in parents would suggest a de-novo mutation. In cases 2 and 3 the mutation was probably inherited from the father, consistent with autosomal dominant pattern of inheritance of FHH. The use of Cinacalcet successfully improved calcium levels and alleviated all the associated symptoms.
\end{abstract}

Volume 6 Issue 2 - 2018

\author{
John Anthonypillai,' Sunil K Sinha,' Andrey \\ Mamkin,' Svetlana Ten,' Qing Dong, ${ }^{2}$ Amrit \\ Bhangoo ${ }^{3}$ \\ 'Pediatric Endocrinology, State University of New York \\ Downstate Children's Hospital \& Infants and Children Hospital \\ of Brooklyn at Maimonides, USA \\ ${ }^{2}$ Pediatric Endocrinology University of California, USA \\ ${ }^{3}$ Children's Hospital of Orange County \& University of \\ California, USA
}

Correspondence: Amrit Bhangoo, Children's Hospital of Orange County \& University of California, I 20 I W. La Veta Ave, Orange, CA 92868, USA, Fax 7l4 509 3300, Tel 7/4 509 8634, Email drapsbhangoo@yahoo.com

Received: August 30, 2017 | Published: April 06, 2018
Abbreviations: FHH, Familial hypercalcemia hypocalciuria; CaSR, Calcium Sensing 20 Receptor; PTH, Parathyroid Hormone

\section{Introduction}

Familial hypocalciuric hypercalcemia $(\mathrm{FHH})$ is a metabolic abnormality that is usually asymptomatic. Occasionally, patients may complain of weakness, fatigue, polydipsia, and psychiatric disorders. It is present in about $2 \%$ of patients and the survival rates of affected patients are no different than those in the general population. ${ }^{1} \mathrm{FHH}$ is an autosomal dominant disorder with high penetrance. Most people with FHH have heterozygous loss of function mutations in the Calcium Sensing Receptor (CaSR) gene. Common mutations locus associated with FHH occur on chromosomes 3 and 19 (19p13.3 and 19q13). ${ }^{2,3}$ The CaSR is expressed in the parathyroid, thyroid, kidney, gut, pancreas, and bone. In a CaSR with normal function, high $\mathrm{Ca}$ concentrations stimulate the CASRs, which signal calcitonin production and urinary $\mathrm{Ca}$ excretion, while suppressing the synthesis of parathyroid hormone (PTH). ${ }^{1}$ The CaSR mutation in FHH results in reduced sensitivity of CaSRs to circulating calcium. The decreased receptor sensitivity in the distal nephron of the kidney results in hypocalciuria. ${ }^{4}$ As a result of the decreased sensitivity to calcium, a normal level of calcium is perceived as low by the parathyroid and PTH is released to bring up the calcium concentration. Thus the kidney res- ponds by reducing calcium excretion in the urine as the CaSR has reduced sensitivity to high circulation calcium levels., ${ }^{2,3}$

The urinary calcium: creatinine ratio is important to distinguish FHH fromprimary hyperparathyroidism, both of them present with hypercalcemia, and hence the urinary calcium: creatinine ratio should be calculated. Hypocalciuria is an important distinguishing feature of FHH but not primary hyperparathyroidism. If the ratio is less than or equal to 0.01 , then the result is suggestive of FHH. However, $20 \%$ of FHH patients have been reported to have a ratio greater than 0.01 .5 So, urine concentrations of calcium can be normal in $\mathrm{FHH}$, while the urine is diluted in primary hyperparathyroidism. Whereas the urinary calcium: creatinine ratio in primary hyperparathyroidism is higher A CaSR mutation analysis can be used as an essential tool to arrive at a diagnosis of FHH. ${ }^{1}$ A homozygous loss of function mutation of CaSR results in neonatal severe primary hyperparathyroidism (NSPHT), which has a more severe presentation than FHH. This condition presents in the neonatal period with hypercalcemia, parathyroid gland hyperplaisia, hypotonia, dehydration, bone demineralization, fractures, polyuria, failure to thrive, and respiratory distress. ${ }^{1,3}$ There currently is no FDA (Food and Drug Administration) approved treatment for FHH or NSPHT. Parathyroidectomy is an effective treatment option in NSPHT, but with significant risk for complications. FHH is often left untreated and patients are counseled regarding the benign 
nature of symptoms. There are some previous reports that Cinacalcet may be helpful in treating patients with FHH..$^{6-9}$ In this study we report a successful treatment and alleviation of symptoms with use of Cinacalcet use in patients with FHH and mutations in the CaSR gene.

\section{Materials and methods}

\section{Patient description}

Case 1: An 8 year old female was diagnosed with hypercalcemia at the age of 3 years. She was complaining of constipation, polyuria and nocturia but there was no relevant family history of hypercalcemia. The mother and father serum calcium levels were normal. She had a markedly elevated serum calcium level $(14.9 \mathrm{mg} / \mathrm{dL})$, a normal $\mathrm{EKG}$, and was treated with IV fluids and furosemide. She was admitted to PICU and discharged home after uneventful course except for high serum calcium. Urinary $\mathrm{Ca}$ excretion was markedly decreased. Neck ultrasound and sestamibi scan were unable to localize any nodule or parathyroid glands enlargement. Renal sonogram revealed no renal calcifications. Further laboratory evaluation showed serum phosphorus $2.9 \mathrm{mg} / \mathrm{dL}$, The PTH concentrations varied between 121 $169 \mathrm{pg} / \mathrm{mL}$ (9-59 pg/mL), Vitamin D-25 hydroxy was low at 18, secondary to Vitamin-D deficiency. The urinary calcium/creatinine ratio was extremely low at 0.001 . Since then she was followed by the endocrine clinic regularly without any intervention until 7 years of age. Due to significant polyuria, a trial of Cinacalcet was initiated, which

Case 2: A 7 year old male was sent to the Pediatric Endocrine clinic by pediatrician for the evaluation of the continuous high serum calcium level $(11.3 \mathrm{mg} / \mathrm{dL})$. The patient complained of occasional leg pains. He was diagnosed with bipolar disorder prior to the visit, which was well controlled on medications. Patient had a DEXA scan which did not show any osteoporosis or osteopenia (Bone mineral density $\mathrm{Z}$ score: +1.6 to +1.8 ). Renal Sonogram was also normal. Laboratory evaluation showed serum phosphorus of $4.2 \mathrm{mg} / \mathrm{dL}$, a high intact PTH (69 mg/dL), and normal vitamin D-25 and vitamin D-1,25 levels (see Table). He was started on Cinacalcet $30 \mathrm{mg}$ twice a day. Over the course of treatment his calcium levels were normalized $(9.5 \mathrm{mg} / \mathrm{dL})$ and his leg pain resolved. The laboratory assessment after the start of Cinacalcet showed an increase in serum phosphorus $(5.1 \mathrm{mg} / \mathrm{dL})$ and PTH $(80.6 \mathrm{mg} / \mathrm{dL})$. Case 2 was followed for 4 years with normocalcemia.

Table I The table changes in the biochemical and hormonal profile of the 3 patients with $\mathrm{FHH}$, who were treated by Cinacalcet

\begin{tabular}{|c|c|c|c|c|c|c|c|}
\hline & \multicolumn{3}{|c|}{ Case I } & \multicolumn{2}{|c|}{ Case 2} & \multicolumn{2}{|c|}{ Case 3} \\
\hline & Norms & $\begin{array}{l}\text { Prior } \\
\text { cinacalcet }\end{array}$ & $\begin{array}{l}\text { After } \\
\text { cinacalcet }\end{array}$ & Prior & After & Prior & After \\
\hline Calcium & $\begin{array}{l}8.9-10.4 \mathrm{mg} / \\
\mathrm{dL}\end{array}$ & 14.9 & 10.3 & 11.3 & 9.5 & 11.1 & 9.8 \\
\hline Phosphorus & $4.5-8 \mathrm{mg} / \mathrm{dL}$ & 2.9 & 3.5 & 4.2 & 5.1 & 3.7 & 4.5 \\
\hline Magnesium & $2-3.5 \mathrm{mg} / \mathrm{dL}$ & 2.4 & - & 2.5 & - & 2.3 & - \\
\hline Intact-PTH & $9-59 \mathrm{pg} / \mathrm{mL}$ & $121-169$ & 93.7 & 69 & 80.6 & 44 & 40 \\
\hline \multicolumn{2}{|c|}{ Urinary calcium/creatinine ratio } & 0.001 & 0.02 & I.I & - & - & - \\
\hline $\begin{array}{l}\text { Vitamin D } \\
\text { 25-Hydroxy }\end{array}$ & $32-100 \mathrm{ng} / \mathrm{mL}$ & 18 & 27 & 31.9 & 45 & 40 & 39 \\
\hline $\begin{array}{l}\text { Vitamin D I, } 25 \\
\text { Dihydoxy }\end{array}$ & $27-71 \mathrm{pg} / \mathrm{mL}$ & 51 & - & 65 & 57 & 65 & 47 \\
\hline $\begin{array}{l}\text { Alkaline } \\
\text { Phosphatase }\end{array}$ & $93-309 \mathrm{ng} / \mathrm{mL}$ & - & 374 & 42 & - & 201 & 188 \\
\hline
\end{tabular}

Citation: Anthonypillai J, Sinha SK, Mamkin A, et al. Experience with cinacalcet in familial hypocalciuric hypercalcemia resulting from inactivating mutations in calcium sensing receptor (CaSR). Endocrinol Metab Int J. 20I8;6(2):I37-I40. DOI: I0.I5406/emij.2018.06.00I67 provided symptomatic relief with increased urinary calcium excretion along with decreased serum calcium and PTH levels (Figure 1). When $60 \mathrm{mg}$ of Cinacalcet was given serum calcium dropped to $11.8 \mathrm{mg} / \mathrm{dL}$, $120 \mathrm{mg}$ of Cinacalcet resulted in serum calcium of 11.2 , and $240 \mathrm{mg}$ of Cinacalcet resulted in serum calcium of 10.3. After the administration of Cinacalcet, serum phosphorus increased $(3.5 \mathrm{mg} / \mathrm{dL}), \mathrm{PTH}$ decreased $(93.7 \mathrm{pg} / \mathrm{mL})$ and urinary calcium/creatinine ratio was increased to 0.02 .

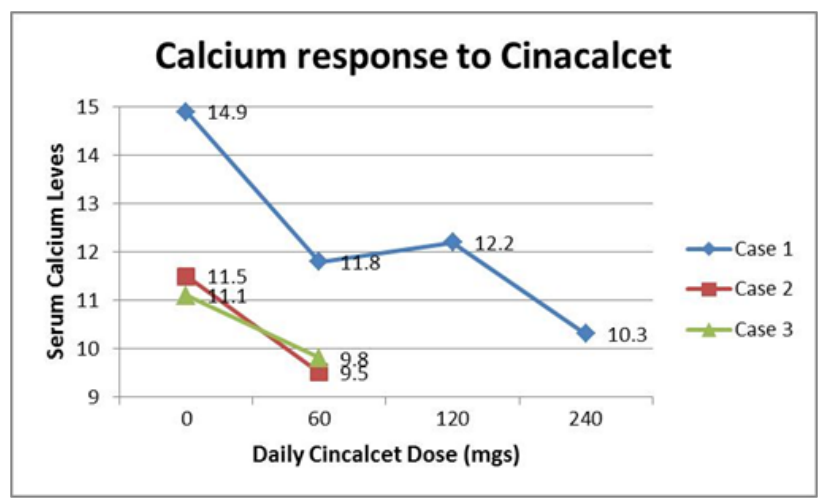

Figure 1 Shows the decrease in serum calcium levels of the 3 cases with CaSR mutations which were treated with Cinacalcet. Case was treated with the high dose upto $240 \mathrm{mg}$ /day of Cinacalcet divided twice a day. The other 2 case were treated with $60 \mathrm{mg}$ /day divided twice a day.

Case 3: A 6 year old boy younger brother of Case 2 was referred to our clinic by pediatrician for the evaluation of the high serum calcium level $(11.1 \mathrm{mg} / \mathrm{dL})$. At the time of presentation he had no acute complaints and past medical history was non-contributory. Family history is significant for hypercalcemia in the father who appeared asymptomatic. Physical exam was normal. Renal and Thyroid sonogram were normal. Patient had a DEXA scan on which did not indicate any osteoporosis or osteopenia. MRI of head and neck were also performed and did not show anything suggestive of a parathyroid adenoma. The laboratory evaluation showed serum phosphorus of $3.7 \mathrm{mg} / \mathrm{dL}$, normal PTH $(44 \mathrm{pg} / \mathrm{mL})$ and normal vitamin-D 25 and vitamin-D 1, 25 (Table 1). Patient was started on Cinacalcet $30 \mathrm{mg}$ twice a day, and his calcium concentrations decreased to normal ranges $(9.8 \mathrm{mg} / \mathrm{dL})$. Serum Phosphorus increased $(4.5 \mathrm{mg} / \mathrm{dL})$ and PTH decreased slightly to $40 \mathrm{pg} / \mathrm{mL}$. Case 3 was followed for 4 years as well and has been normocalcemic. 


\section{Materials and methods}

\section{Hormonal testing}

Vitamin D, 25-Hydroxy and Vitamin D, 1, 25-Dihydroxy were measured byHPLC-MS mass spectrometry. The Intact Parathyroid Hormone (IPTH) was measured by immunoenzymetric assay. DNA isolation and sequencing DNA was extracted from peripheral leukocytes and all exons of the CaSR genes were amplified by PCR using primer pairs and standard conditions. Written informed consent and assent to do the mutational analysis was obtained from the parents and subjects respectively. The study was approved by the Institutional Review Board of University of California, San Francisco.

\section{Results}

Mutation analysis of the CASR gene from peripheral leukocyte from case 1 revealed a previously described heterozygous missense mutation (CGA-CAA, R185Q). In case 2 and case 3 a heterozygous mutation (GCC->ACC, A194T) was found in the extracellular domain in the CaSR encoded by exon 4 of the CASR gene and in the unaffected father. The mother's genomic DNA is of normal sequence.

\section{Discussion}

Calcimimetics are allosteric modulators of CaSR that make the mutant receptormore sensitive to serum calcium levels. This increased sensitivity results in a reduction of PTH and serum calcium levels. Cinacalcet is currently the only drug in this class approved for human use and is currently indicated for treatment of secondary hyperparathyroidism in patients with chronic kidney disease and for the treatment of hypercalcemia in patients with primary hyperparathyroidism. ${ }^{9-18}$ Cinacalcet has been used in cases with FHH but currently is not FDA approved for treatment of FHH or NSPHT. Cinacalcet is usually well tolerated the most reported side effects are nausea and vomiting. ${ }^{12,17}$

FHH is considered a benign entity because it is often asymptomatic and cardiac abnormalities or cardiac dysrythmias are not associated with the high serum calcium levels. ${ }^{1}$ However, in our cases, patients complained of polyuria, nocturia, enuresis, and constipation which were all relieved on administration of Cinacalcet and correction of hypercalcemia. These symptoms although not as a serious as the cardiac manifestations, but were severe enough to the effect the normal functioning of daily activities. The symptoms reported by patients were often restricting and at times debilitating.

In all three of our cases, serum calcium levels were reduced to within normallimits and serum phosphorus was increased after administration of Cinacalcet. Serum PTH levels were decreased in both cases 1 and 3 after Cinacalcet administration. In addition to our cases, Cinacalcet has been used in both adult and pediatric patients to treat FHH and NSHPT. ${ }^{6-8,19}$ These results are similar to cases presented in a 37 year old woman with FHH suffering from recurrent pancreatitis due to hypercalcemia. ${ }^{7}$ Similarly Cinacalcet was used in a 26 year old male with psychosis, hypercalcemia and osteoporosis. ${ }^{6}$ In a pediatric case report a 6 year old boy with FHH was described with dense tympanosclerosis involving multiple calcium deposits, whose condition improved with surgical revision and treatment with Cinacalcet which resulted in the surgical scar healing without excessive calcium deposits. $^{8}$

\section{Conclusion}

In conclusion, our experience with Cinacalcet in treating pediatric patients with $\mathrm{FHH}$, in addition to the few reports involving adults and a child, support the beneficial effects by alleviation of symptoms of polyuria, nocturia, enuresis and constipation after calcimimetic administration in patients with loss of function mutations of the CaSR. We reported a novel mutation of CaSR in a severe presentation in case 1 and lack of symptoms in parents would suggest a de-novo mutation. Whereas, in the two brothers was probably inherited from the father, consistent with autosomal dominant pattern of inheritance of FHH.

\section{Acknowledgment}

None.

\section{Conflict of interest}

None to declare.

\section{References}

1. Varghese J, Rich T, Jimenez C. Benign familial hypocalciurichypercalcemia. Endocr Pract. 2011;17(Suppl 1):1317.

2. Msaouel P, Nixon AM, Bramos AP, et al. Extracellular calcium sensing receptor: an overview ofphysiology, pathophysiology and clinical perspectives. In Vivo. 2004;18(6):739-753.

3. Hendy GN, D'Souza-Li L, Yang B, et al. Mutations of the calciumsensing receptor (CASR) in familial hypocalciuric hypercalcemia, neonatal severe hyperparathyroidism, and autosomal dominant hypocalcemia. Hum Mutat. 2000;16(4):281-296.

4. Lietman SA, Germain-Lee EL, Levine MA. Levine, Hypercalcemia in childrenand adolescents. Curr Opin Pediatr. 2010;22(4):508515 .

5. Heath DA. Familial hypocalciuric hypercalcemia. Rev Endocr Metab Disord. 2000;1(4):291-296.

6. Timmers HJ, Karperien M, Hamdy NA, et al. Normalization of serum calcium by cinacalcet in a patientwith hypercalcaemia due to a de novo inactivating mutation of the calcium-sensing receptor. J Intern Med. 2006;260(2):177-182.

7. Festen-Spanjer B, Haring CM, Koster JB, et al. Correction of hypercalcaemia by cinacalcet in familialhypocalciuric hypercalcaemia. Clin Endocrinol (Oxf). 2008;68(2):324-325.

8. Alon US, VandeVoorde RG. Beneficial effect of cinacalcet in a child with familial hypocalciuric hypercalcemia. Pediatr Nephrol. 2010;25(9):1747-1750.

9. Lu JY, Yang Y, Gnacadja G, et al. Effect of the calcimimetic R-568 [3-(2-chlorophenyl)-N-((1R)-1- (3-methoxyphenyl) ethyl)-1-propanamine] on correcting inactivating mutations inthe human calcium-sensing receptor. J Pharmacol Exp Ther. 2009;331(3):775-786.

10. Block G. Calcium, Calcimimetics and Clinical Outcomes. Clin J Am Soc Nephrol. 2006;1(2):170-171.

11. Bover J, Aguilar A, Baas J, et al. Calcimimetics in the chronic 
kidney disease-mineral and bonedisorder. Int $J$ Artif Organs. 2009;32(2):108-121.

12. Lindberg JS, Culleton B, Wong $\mathrm{G}$, et al. Cinacalcet $\mathrm{HCl}$, an Oral Calcimimetic Agent for the Treatment ofSecondary Hyperparathyroidism in Hemodialysis and Peritoneal Dialysis: ARandomized, Double-Blind, Multicenter Study. J Am Soc Nephrol. 2005;16(3):800-807.

13. Shoback DM, Bilezikian JP, Turner SA, et al. The Calcimimetic Cinacalcet Normalizes Serum Calcium inSubjects with Primary Hyperparathyroidism. $J$ Clin Endocrinol Metab. 2003;88(12):5644-5649.

14. Brown EM. Clinical utility of calcimimetics targeting the extracellular calcium-sensing receptor (CaSR). Biochem Pharmacol. 2010;80(3):297-307.
15. Goodman WG. Calcimimetic agents and secondary hyperparathyroidism: treatment and prevention. Nephrol Dial Transplant. 2002;17(2):204-207.

16. Guerra R, Auyanet I, Fernandez EJ, et al. Hypercalcemia secondary to persistent hyperparathyroidism in kidney transplant patients: analysis after a year with cinacalcet. J Nephrol. 2011;24(1):78-82.

17. Joy MS, Kshirsagar AV, Franceschini N. Calcimimetics and the Treatment of Primary and Secondary Hyperparathyroidism. Ann Pharmacother. 2004;38(11):1871-1880.

18. Rothe HM, Liangos O, Biggar P, et al. Cinacalcet Treatment of Primary Hyperparathyroidism. Int J Endocrinol. 2011:415719.

19. Wilhelm-Bals A, Parvex P, Magdelaine C, et al. Successful Use of Bisphosphonate and Calcimimetic in Neonatal Severe Primary Hyperparathyroidism. Pediatrics. 2012;129(3):e812-e816. 